\title{
Microstructure Evolution During Creep and Annealing of Minerals and Rocks
}

\author{
E. Mariani,* D.J. Prior, ${ }^{*}$ S.J. Covey-Crump, ${ }^{* *}$ J. Mecklenburgh,** D. Tatham* and J. Wheeler, ${ }^{*}$ \\ * Department of Earth and Ocean Sciences, University of Liverpool, Liverpool, L69 3GP, UK \\ ** School of Earth, Atmospheric and Environmental Sciences, University of Manchester, \\ Manchester M13 9PL, UK
}

In the Earth's crust and mantle syn-tectonic (dynamic) and post-tectonic (static) recrystallization of rocks can modify grain sizes, shapes and crystallographic orientations [1]. This affects physical properties and anisotropies and is central to the interpretation of the mechanical behavior of rocks in major fault zones along plate boundaries, geological terrains in mountain belts [2] and seismic anisotropy data. Bulk measurements of lattice preferred orientations (LPOs), using texture goniometry and more recently neutron and synchrotron techniques, have been available since the middle of last century. However in the last 2 decades the advent of electron backscatter diffraction (EBSD) in the scanning electron microscope (SEM) has offered the opportunity to measure spatially resolved crystallographic misorientations between grains in the same mineral and/or between phases [3]. Particularly, EBSD in the SEM is essential to our understanding of recovery, recrystallization and grain growth during dislocation creep and annealing of minerals and rocks. Recrystallization models, such as sub-grain rotation, grain boundary bulging and migration, currently applied in the Earth sciences produce microstructures that can be tested using EBSD. Data available mainly on rocksalt, olivine and $\mathrm{MgO}$ [4; 5] are consistent with current recrystallization models (Fig.1a), however microstructures observed in calcite, quartz, plagioclase and orthopyroxene (all minerals that twin) cannot be accounted for by such models alone $[6 ; 7]$. These show that newly recrystallized grains are characterized by high misorientation angles between each other and to their parent grains (Fig.1b), and display near to random misorientation axis distributions. Grain boundary sliding has been proposed as a deformation mechanism that could account for these observations.

More recently we have observed that the same microstructures could be explained by sub-grain rotation, grain boundary bulging and migration assisted by the presence of twin boundaries. This can result in complex, segmented boundaries that may be unstable and rapidly become general high angle boundaries (Fig.2a and b) [8]. To date this twin assisted recrystallization mechanism has been documented only in experimentally deformed then annealed rock samples, it occurs rapidly and evidence of its evolution is difficult to gather in final microstructures.

In order to identify twin assisted recrystallization confidently in deformed and annealed microstructures, new EBSD data on general and special boundary geometries, misorientations, grain distortions, dynamics and kinematics of low and high angle grain boundary migration are needed. These may be achieved by performing in-situ annealing experiments in the SEM [9] on suitable geological materials, such as for example anhydrite. Nonetheless such experiments are challenging and should always be substantiated by standard rock deformation tests. A novel time-series EBSD analysis technique is currently under development. This uses a custom built SEM stage to analyze cylindrical sample surfaces accurately and sequentially, after each stress, strain, temperature or time increment achieved in a deformation apparatus. Thus time-series EBSD coupled with rock deformation experiments for the first time, will yield information on microstructure evolution at the scale of individual grains and grain boundaries. This will be the basis upon which more realistic recrystallization models can be constructed and will underpin our interpretation of syn- and posttectonic processes in the Earth's crust and mantle. 
References

[1] J.-P. Poirier et al., Bulletin de Minéralogie, 102 (1979) 67.

[2] E.H. Rutter et al., Geologische Rundschau, 77 (1988) 295.

[3] D.J. Prior et al., In Electron Backscatter Diffraction in Materials Science: 2nd Edition, 2009.

[4] J.L. Urai et al., In Mineral and Rock Deformation: Laboratory Studies, American Geophysical Union, Washington, D.C., 1986, 161.

[5] E. Mariani et al., Acta Materialia, doi:10.1016/j.actamat.2008.12.029 (2009).

[6] M. Bestmann et al., Journal of Structural Geology, 25 (2003) 1597.

[7] A. Halfpenny et al., Tectonophysics, 427 (2006) 3.

[8] E. Mariani et al., Journal of Structural Geology, In Preparation (2009).

[9] S. Piazolo et al., Tectonophysics, 427 (2006) 55.

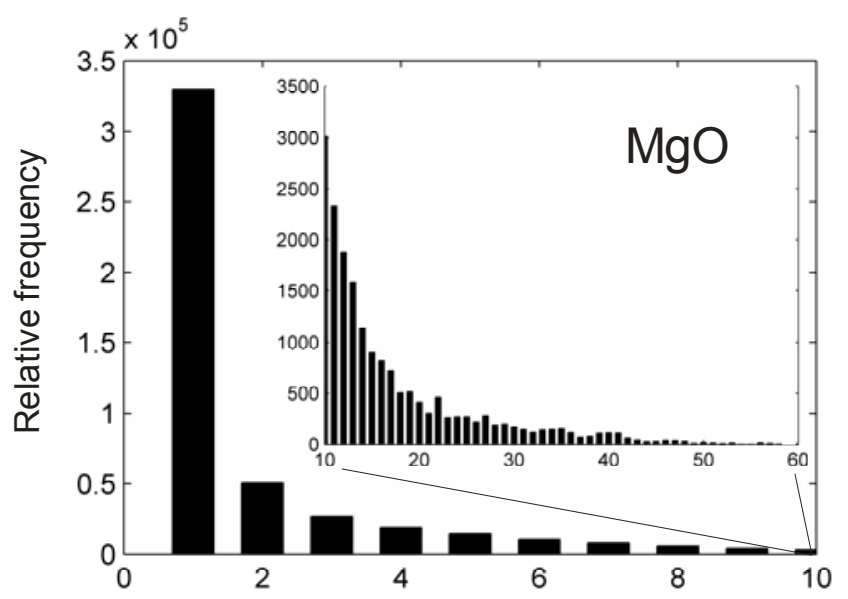

a

Neighbour pair misorientation angle distribution

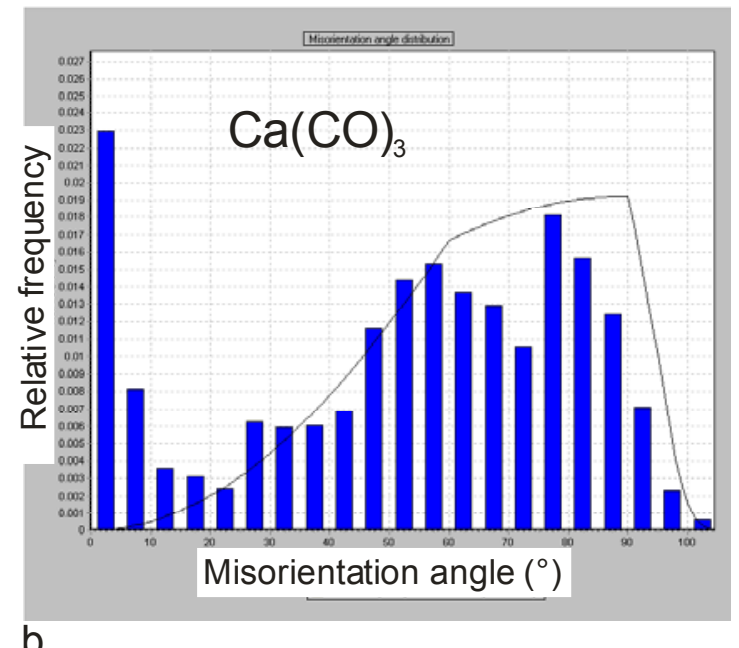

b

FIG. 1. Neighbour-pair misorientation angle distributions of a deformed $\mathrm{MgO}$, showing continuous exponential decrease of relative frequency to very high misorientation angles, and $\mathbf{b}$ cold worked then annealed Carrara marble. This shows a discontinuous misorientation angle distribution.
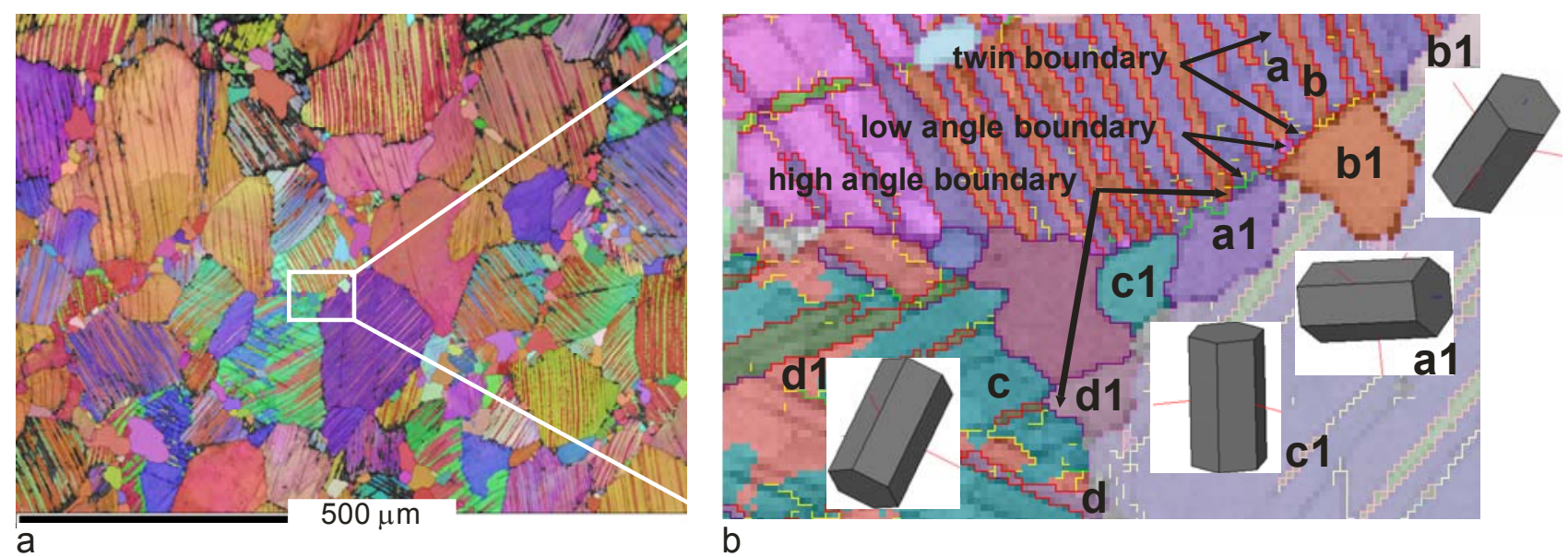

FIG. 2. a Inverse pole figure color coding EBSD map of cold worked then annealed calcite. b Detail of Fig. 2 a: New grains a1, b1, c1, and d1 have formed from parent grains a and c and twins of the parent grains $b$ and $d$ by sub-grain rotation and boundary bulging. Boundaries between new grains and parent + twin are complex and formed of twin (red), low angle (yellow and green) and high angle (purple) boundary segments (black arrows). New grain orientations are at high angle to each other (solid prisms). Complex boundaries rapidly become high angle general boundaries. 